\title{
Healthy lifestyles and body mass index as correlates of body image dissatisfaction in primary schoolchildren
}

\author{
Luis Calmeiro ${ }^{1,2, *}$ and Carlos Pereira ${ }^{3}$ \\ ${ }^{I}$ School of Applied Sciences, Abertay University, Dundee, United Kingdom; ${ }^{2}$ Institute of Environmental Health of the Fac- \\ ulty of Medicine, University of Lisbon, Lisbon, Portugal; and ${ }^{3}$ City Council of Vila Real de Santo António, Vila Real de \\ Santo António, Portugal
}

Copyright: (C) 2019 L. Calmeiro and C. Pereira. This is an open access article licensed under the Creative Commons Attribution License (https://creativecommons.org/licenses/by/4.0/).

Background: Body image is a representation of the self that develops from an early age. Such representations are likely to be associated with lifestyle choices. Objective: The purpose of this study was to explore the relationships between health behaviours (i.e., physical activity, screen time and adherence to the Mediterranean diet), body mass index (BMI) and body image dissatisfaction among primary schoolchildren. Methods: A total of 782 pupils (age $7.92 \pm 1.36$ years), 405 boys (age $8.01 \pm 1.38$ years) and 377 girls (age $7.95 \pm 1.33$ years) from the Southeast region of Portugal, answered a survey containing the Mediterranean Diet Quality Index (KIDMED) to measure eating patterns and gender congruent Figure Rating Scales to measure body image dissatisfaction. Children also had their weight and height measured to calculate BMI. Based on the Krece Plus quick test, parents reported on children's physical activity and screen time. Results: Girls reported being less active, $t(619)=2.29, p=.022, d=0.19$; adhering more to the Mediterranean diet, $t(775)=-3.92, p<.001, d=-0.29$; and having higher body image dissatisfaction than boys, $t(773)=-2.53, p=.012$, $d=-0.19$. There was a significant association between BMI and body image dissatisfaction, $\chi^{2}(4)=79.34, p<.001$. Moreover, $22.5 \%$ of the children with normal BMI perceived being overweight/obese. Gender $(\beta=0.085, p=.036)$ and BMI $(\beta=0.40, p<.001)$, but not lifestyle variables, predicted body image dissatisfaction $\left(R^{2}=.173\right)$. Conclusions: Physical activity, screen time, and adherence to a Mediterranean diet were not associated with body image dissatisfaction. However, BMI was positively associated with body image dissatisfaction. Children are not accurate in estimating their body size which can lead to body image dissatisfaction and attempts to control body weight.

Keywords: child obesity, Mediterranean diet, physical activity, screen time, self-perception

\section{Introduction}

Body image is a self-perception that represents the "manner we view our own body and the mental representations we have of it" (Davis 1997, p. 145). These mental representations develop from an early age, even before puberty (Sands, Tricker, Sherman, Armatas \& Maschette, 1997). Children, particularly girls, as young as five years old have reported body image concerns (Dohnt \& Tiggemann, 2006) and $40 \%$ to $50 \%$ of children aged six to 12 years old stated being dissatisfied with their appearance (Smolak, 2011).

Literature suggests that a negative body image is associated with gender (being female), age, and high

\footnotetext{
* Address for correspondence: Luis Calmeiro, Division of Sport and Exercise Sciences, School of Applied Sciences, Abertay University, Bell Street, DD1 HG, Dundee, United Kingdom. E-mail: 1.calmeiro@abertay.ac.uk
}

body mass index (BMI) in children aged 6-11 years old. Generally, girls tend to prefer a thinner body while boys prefer a larger body. Dissatisfaction with the body increases with age as adolescents become more aware of social-prescribed ideals of the body and are more vulnerable to comparison with peers (Dion et al., 2016; Ricciardelli \& McCabe, 2001). The relationship of body image with BMI is particularly alarming as the prevalence of overweight and obesity in children (7-9 years old) is as high as $31.5 \%$ (Padez, Fernandes, Mourão, Moreira, \& Rosado, 2004). In addition, in a study conducted with Portuguese children (7-10 years old), BMI predicted $25.6 \%$ in boys and $30.8 \%$ girls' dissatisfaction with their body shape (Coelho, Padez, Moreira, Rosado, \& Mourao-Carvalha, 2013). Duchin et al. (2014) further confirmed BMI as the strongest predictor of body image dissatisfaction of 5-12-year-olds; in addition, body image dissatisfaction may have a long-term negative effect as it significantly influenced further weight gain 
after 32 months (Duchin et al., 2015). Taken together, this body of evidence suggests the need to address the implications of weight perceptions in addition to actual weight (Ali, Fang, \& Rizzo, 2010).

A discrepancy between one's current body image and ideal body image underlines body imagine dissatisfaction. This dissatisfaction may lead to excessive body concerns, which in turn may result in the adoption of maladaptive forms of weight control or in sedentary behaviour (Duchin et al., 2015). In this regard, girls may be more at risk of engaging in maladaptive behaviours than boys because of girls' stronger internalisation of social cultural pressures to be thin (Tatangelo \& Ricciardelli, 2015). However, early engagement in healthy lifestyles, defined as a set of health-promoting behaviours (Calmeiro \& Matos, 2016), may result in more favourable and balanced image of one's body. Particularly, lower levels of physical activity and higher levels of sedentary behaviour (Andersen, Crespo, Bartlett, Cheskin, \& Pratt, 1998; Trost, Kerr, Ward, \& Pate, 2001), and lack of adherence to a Mediterranean diet (Brill, 2009; Cömert, Çerkez, Tekin, Aydoğan, \& Esşiz, 2015) have been shown to be associated with excessive body weight, unsatisfactory self-perceptions and reduced quality of life (Petracci \& Cavrini, 2013).

The purpose of the current study is to explore the extent to which body image is associated with lifestyles, notably physical activity, screen time and Mediterranean diet, and weight status in primary school-children. We hypothesise (a) a positive association between screen time and BMI with body image dissatisfaction, and (b) a negative association between physical activity and Mediterranean diet with body image dissatisfaction. However, due to the different social and media influences concerning the ideal body, weight status may interact with gender to influence the way children evaluate their body (Shriver et al., 2013). In addition, we also explore how accurate children's body image is in relation to their weight status as indicated by their BMI.

\section{Methods}

\section{Participants}

The sample was composed of 782 schoolchildren (mean age $7.98 \pm 1.36$ years), 405 boys (age $8.01 \pm 1.38$ years) and 377 girls (age $7.95 \pm 1.33$ years) from primary 1 $(n=184$; age $6.31 \pm 0.53$ years, range $5-8)$, primary 2 $(n=182 ;$ age $=7.37 \pm 0.55$ years, range 6-9), primary 3 $(n=195 ;$ age $=8.43 \pm 0.70$ years, range $8-12)$, and primary $4(n=221$; age $=9.47 \pm 0.73$ years, range $8-12)$.

The Regional Educational Authority provided the ethical approval of this study to be conducted in accordance with the 1964 Helsinki Declaration. The local city council coordinated recruitment in conjunction with primary schools. All schools are public, hence fully paid by the government. All children who attended one of the five primary schools in this specific south-eastern region of Portugal and their legal guardians were invited to participate in this study. Informed consent was obtained, participation was voluntary and confidentiality was guaranteed. Data collection took place in the children's schools during regular school days; children who missed school on those days were not assessed later for inclusion. Overall, data collection covered $87 \%$ of the student population.

\section{Measures}

Physical activity and screen time were assessed through single item questions based on Krece Plus quick test (Llargues et al., 2011), whereby parents estimated (a) how many hours weekly, on average, do their child spend doing out-of-school physical activity (from " 0 hours" to "5+ hours") and (b) how many hours daily, on average, do their children spend watching TV and playing video games.

Eating patterns were measured by the Mediterranean Diet Quality Index (KIDMED). The KIDMED index represents healthy eating in children and adolescents (Leal, Oliveira, \& Pereira, 2016) and its scores have been associated with protective effects against obesity and chronic degenerative diseases (Brill, 2009). The KIDMED questionnaire is composed of 16 questions that aim to determine the extent to which children incorporate particular types of food into their diet. To each question, children answer "yes" or "no". The final score is the sum to all yes questions (" 1 " or "- 1 ") and it can vary from -4 to 12 . The adherence to Mediterranean diet can be categorised in three levels (Serra-Majem et al., 2004): high (> 7), moderate (4 to 7) and low $(<4)$.

BMI was calculated by obtaining actual measures of body mass $(\mathrm{kg})$ and height $(\mathrm{m})$ according to the formula mass/height ${ }^{2}$. Children were classified as underweight, normal weight, overweight and obese according to the criteria of the World Health Organization (Wijnhoven et al., 2013). Specifically, BMI-for-age were compared to $z$-scores and the following cut-off points were used: $z$-score $<-1 S D$ (underweight), $-1 S D \geq z$-score $\leq 1$ $S D$ (normal weight), $z$-score $>1 S D$ (overweight), and $z$-score $>2 S D$ (obese).

A trained research assistant collected the data following a standardised measurement protocol. Weight was measured using a calibrated electronic scale, model Tanita BC 418 MA segmental (Tanita Corporation, Tokyo, Japan), with a precision of $\pm 0.2 \mathrm{~kg}$. Children were using shorts, T-shirts, and were without shoes. Height was measured to the nearest millimetre while 
children stood without shoes against a free-standing portable stadiometer, model SECA 213 (Seca, Hamburg, Germany).

Body image dissatisfaction. Gender congruent Figure Rating Scales (Stunkard, Sorenson, \& Schulsinger, 1983) were presented to boys and girls to measure perceptions of their current and ideal body sizes. Out of seven silhouettes, ranging from extreme thinness to extreme obesity, children indicated which silhouettes best represented their current body and their desired body (i.e., ideal body). Body image dissatisfaction was the difference between the current body image and desired body image: a higher score on current body image represents a perception of being heavy, while a lower score on current body image represents a perception of being thin. The validity of Stunkard's figure rating scales in Portuguese populations has been demonstrated in a variety of samples (e.g., Adami et al., 2012; Scagliusi et al., 2006).

\section{Procedure}

After parental consent was obtained, a research assistant conducted face-to-face interviews with each individual participant. In these interviews, the research assistant read each question related to dietary habits and body image to the children and recorded their answers. Then, children's weight and height were measured. Parents received the Krece Plus quick test questionnaire concerning their children's physical activity and screen time patterns. Parents sent their completed questionnaire in a closed envelope to the researcher with an $82 \%$ return rate.

\section{Analysis}

Mean and standard deviations were used to characterise the sample for all variables. Pearson moment-product correlations were calculated to explore the associations between all variables. Independent $t$-tests were conducted to compare the variables between boys and girls and effect sizes were calculated using the mean difference between boys and girls divided by the pool standard deviation; values of 0.2 were considered small, 0.5 were moderate and $>0.8$ were large (Cohen, 1988).

A one-way analysis of variance was used to calculate differences in BMI between participants across the seven Figure Rating Scales silhouettes. Scheffe's tests were used as post hoc pairwise comparisons.

BMI categories and body image dissatisfaction categories were cross-tabulated and chi-squares were computed to determine the level of associations between these variables. To predict body image dissatisfaction all variables were centred and a sequential regression analysis was conducted. Interaction terms with gender were calculated to analyse the potential moderating role of gender. In both regression analyses, age and gender were entered in step 1 , followed by screen time, physical activity and adherence to the Mediterranean diet in step 2, BMI in step 3, and finally interaction terms of these variables with gender in step 4 . To determine statistical significance, a $p<.05$ was used. All analyses were conducted on IBM SPSS Statistics (Version 25; IBM, Armonk, NY, USA).

\section{Results}

All variables were deemed normally distributed. Five multivariate outliers, with a Mahalanobis distance $>22.46$, were identified and deleted. Table 1 illustrates the correlation matrix (Pearson productmoment correlation) and Table 2 shows the means and standard deviations for each variable for boys and girls, as well as the results of the $t$-tests and effect sizes for gender comparisons.

Boys and girls did not differ in age (boys $8.01 \pm 1.38$ years, girls $7.95 \pm 1.33$ years; $t(775)=0.62, p=.53$ ). Significant differences between boys and girls were found for out-of-school physical activity, $t(619)=2.29$, $p=.022, d=0.19$; KIDMED index, $t(775)=-3.92$, $p<.001, d=-0.29$; and body image dissatisfaction,

Table 1

Pearson product-moment correlations between all variables

\begin{tabular}{lccccc}
\hline Variable & PA & KIDMED & BMI & BI & BID \\
\hline ScreenT & -.02 & -.07 & .01 & -.02 & -.08 \\
PA & & .07 & -.02 & -.03 & -.03 \\
KIDMED & & & .07 & .03 & .08 \\
BMI & & & $.49^{* *}$ & $.40^{* *}$ \\
BI & & & & $.61^{* *}$ \\
\hline
\end{tabular}

Note. $\quad$ ScreenT $=$ screen time $(\mathrm{TV} /$ Video games $) ; \mathrm{PA}=$ out-of-school physical activity; KIDMED

$=$ Mediterranean diet; $\mathrm{BMI}=$ body mass index $(z$-score $) ; \mathrm{BI}=$ body image; $\mathrm{BID}=$ body image dissatisfaction. ${ }^{* *} p<.01$. 
$t(773)=-2.53, p=.012, d=-0.19$. Boys reported being more active than girls, while girls reported higher adherence to the Mediterranean diet and larger body image discrepancy than boys did. The KIDMED index was poor for $14.5 \%$ of the sample, average for $58.7 \%$ and good for $26.8 \%$. Considering the whole sample, $8.0 \%$ were underweight ( $8.0 \%$ of boys and girls), $53.9 \%$ had normal weight $(54.1 \%$ and $53.7 \%$ for boys and girls respectively), $23.6 \%$ were overweight $(21.7 \%$ and $25.5 \%$ ) and $14.5 \%$ were obese (16.2\% and $12.8 \%$ ).

Table 3 shows participants' BMI descriptive statistics as a function of body image silhouette. A one-way analysis of variance revealed significant differences in BMI between the silhouettes, $F(6,766)=46.33$, $p<.001, \eta^{2}=.226$. Scheffe's post hoc tests show that BMI of participants who circled silhouette 1 through 4 was significantly lower than the BMI of those who have chosen silhouettes 5 through 7 . Those who circled silhouette 2 had lower BMI than those who circled silhouette 4 and those who circled silhouette 5 had significantly lower BMI than those who circled silhouette 6 .

Table 3 also indicates the percentage of participants who are overweight or obese in each silhouette. Note that this percentage progressively increases from silhouette 1 to silhouette 7 , with silhouette 5 marking a steep increase in BMI. This percentage suggests some degree of mismatch between the silhouette chosen (how they see themselves) and their nutritional status.

Table 4 shows the results of the chi-square demonstrating a significant association between BMI categorisation and body image dissatisfaction, $\chi^{2}(6)=90.66$, $p<.001$. This table cross-tabulates the participants' body image dissatisfaction (i.e., whether they think they are too thin, have the ideal weight or they are too heavy) in relation to their BMI. Concerning those who think are too thin (their current body size is smaller than their perceived ideal size), $13.5 \%$ are actually underweight; $68.8 \%$ actually have a normal weight and $17.7 \%$ are actually overweight or obese. Of those who perceive having the ideal weight, $63 \%$ have an accurate perception, while $7.3 \%$ are actually underweight and $29.6 \%$ are overweight or obese. Those who consider being too heavy, $39.5 \%$ are correct, $5.6 \%$ are underweight and $54.9 \%$ have an ideal weight.

Table 5 presents the results of the sequential regression analysis with body image dissatisfaction as the

Table 2

Means, standard deviations, independent t-tests, and effect sizes

\begin{tabular}{|c|c|c|c|c|c|c|c|c|}
\hline \multirow[b]{2}{*}{ Variable } & \multicolumn{2}{|c|}{ Full sample } & \multicolumn{2}{|c|}{ Boys } & \multicolumn{2}{|c|}{ Girls } & \multicolumn{2}{|c|}{ Boys vs. Girls } \\
\hline & Mean & $S D$ & Mean & $S D$ & Mean & $S D$ & $t$-test & Cohen's $a$ \\
\hline ScreenT (hours/day) & 1.86 & 0.94 & 1.86 & 0.97 & 1.86 & 0.90 & 0.06 & 0.00 \\
\hline PA (hours/week) & 2.82 & 1.60 & 2.96 & 1.61 & 2.66 & 1.58 & $2.29 *$ & 0.19 \\
\hline KIDMED ( -4 to 14$)$ & 5.88 & 2.23 & 5.57 & 2.20 & 6.19 & 2.19 & $-3.92 * * *$ & -0.29 \\
\hline BMI (z-score) & 0.65 & 1.21 & 0.69 & 0.22 & 0.60 & 0.19 & 1.10 & 0.44 \\
\hline BI (1 to 7$)$ & 3.86 & 1.07 & 3.84 & 1.07 & 3.95 & 1.07 & -1.45 & -0.10 \\
\hline BID ( -6 to 6$)$ & 0.31 & 1.38 & 0.21 & 1.42 & 0.47 & 1.36 & $-2.53^{*}$ & -0.19 \\
\hline
\end{tabular}

Note. $\quad$ ScreenT $=$ Screen time $($ TV/Video games $) ; \mathrm{PA}=$ out-of-school physical activity; KIDMED = Mediterranean diet; $\mathrm{BMI}=$ body mass index; $\mathrm{BI}=$ body image; $\mathrm{BID}=$ body image dissatisfaction. $\quad{ }^{*} p<.05, * * * p<.001$.

Table 3

Descriptive statistics for body mass index z-score according to body image silhouette and percentage of overweight and obese participants in each silhouette

\begin{tabular}{lrrrccc}
\hline Silhouette number & $n$ & $\%$ & Mean & $S D$ & $95 \%$ CI & \% overweight/obesity \\
\hline 1 & 25 & 3.2 & -0.13 & 1.16 & {$[-0.60,0.35]$} & 2.3 \\
2 & 55 & 7.1 & -0.12 & 1.01 & {$[-0.39,0.15]$} & 14.3 \\
3 & 135 & 17.5 & 0.19 & 0.94 & {$[0.04,0.35]$} & 20.0 \\
4 & 363 & 47.0 & 0.47 & 1.07 & {$[0.36,0.58]$} & 24.2 \\
5 & 158 & 20.4 & 1.44 & 1.03 & {$[1.28,1.61]$} & 67.7 \\
6 & 35 & 4.5 & 2.23 & 1.00 & {$[1.89,2.58]$} & 88.6 \\
7 & 2 & 0.3 & 4.04 & 0.71 & {$[-2.37,10.46]$} & 100.0 \\
\hline
\end{tabular}

Note. $\quad \mathrm{CI}=$ confidence interval. Scheffe post hoc tests: $1,2,3,4<5,6,7 ; 2<4 ; 5<6$. All Scheffe tests were significant at $p<.001$, except for the difference between silhouettes 2 and $4(p=.02)$ and silhouettes 5 and $6(p=.01)$. 
predicted variable. Gender was a significant predictor of body image dissatisfaction (standardised coefficient, $\beta=0.085, p=.036$ ), but it explained only $0.8 \%$ of its variance. The addition of lifestyle variables in step $2 \mathrm{did}$ not significantly improve the model. Conversely, the inclusion of BMI at step 3 accounted for an additional
$15.5 \%$ in the variance of body image dissatisfaction $(\beta=0.40, p<.001)$. Finally, at step 4 , none of the interaction terms significantly improved the regression model. The full model (Model 4) explains $18.1 \%$ of body image dissatisfaction, but only BMI constitutes a significant predictor.

Table 4

Cross tabulation of body mass index and body image dissatisfaction

\begin{tabular}{lccc}
\hline & \multicolumn{3}{c}{ Body image dissatisfaction } \\
\cline { 2 - 4 } Body mass index & Too thin (current < ideal) & Ideal weight (current = ideal) & Too heavy (current > ideal) \\
\hline Underweight & & & \\
Count (\%) & $25(13.5 \%)$ & $18(7.4 \%)$ & $19(5.6 \%)$ \\
Adj. residual & 3.1 & -0.5 & -2.2 \\
Normal & & & $134(39.5 \%)$ \\
Count (\%) & $128(68.8 \%)$ & $3.4(63.0 \%)$ & -7.2 \\
Adj. residual & 4.6 & $52(21.1 \%)$ & $104(30.7 \%)$ \\
Overweight & $24(12.9 \%)$ & -1.0 & 4.3 \\
Count (\%) & -3.9 & $21(8.5 \%)$ & $82(24.2 \%)$ \\
Adj. residual & & -3.2 & 6.7 \\
Obese & $(4.8 \%)$ & $246(100 \%)$ & $339(100 \%)$ \\
Count (\%) & -4.3 & $(100 \%)$ & \\
Adj. residual & $186 \%$ & \\
Total & & & \\
\hline
\end{tabular}

Note. Adjusted residuals with absolute values of 2 (i.e., $|2|$ ) are significant at $p<.05$.

Table 5

Results of a hierarchical regression analysis with body image dissatisfaction as the predicted variable

\begin{tabular}{|c|c|c|c|c|c|c|c|c|}
\hline Step & Predictor & $\begin{array}{l}\text { Unstandardised } \\
\text { coefficient }\end{array}$ & $t$ & $95 \% \mathrm{CI}$ & $R^{2}$ & $F$ change & $\Delta R^{2}$ & $\begin{array}{l}\text { Square } \\
\text { root } \Delta R^{2}\end{array}$ \\
\hline \multirow[t]{3}{*}{1} & & & & & .008 & 2.35 & .008 & .089 \\
\hline & Age & 0.027 & 0.63 & {$[-0.06,0.11]$} & & & & \\
\hline & Gender & 0.233 & $2.12 *$ & {$[0.02,0.46]$} & & & & \\
\hline \multirow[t]{4}{*}{2} & & & & & .017 & 2.02 & .010 & .010 \\
\hline & ScreenT & -0.108 & -1.82 & {$[-0.23,0.01]$} & & & & \\
\hline & PA & -0.026 & -0.75 & {$[-0.09,0.04]$} & & & & \\
\hline & KIDMED & 0.036 & 1.40 & {$[-0.01,0.09]$} & & & & \\
\hline \multirow[t]{2}{*}{3} & & & & & .167 & $114.44^{* * *}$ & .155 & .389 \\
\hline & BMI & 0.452 & $10.70^{* * *}$ & {$[0.37,0.54]$} & & & & \\
\hline \multirow[t]{6}{*}{4} & & & & & .181 & 1.21 & .008 & .089 \\
\hline & Age vs. Gender & -0.112 & -1.40 & {$[-0.27,0.05]$} & & & & \\
\hline & ScreenT vs. Gender & 0.015 & -0.13 & {$[-0.20,0.23]$} & & & & \\
\hline & PA vs. Gender & 0.053 & 0.82 & {$[-0.07,0.18]$} & & & & \\
\hline & KIDMED vs. Gender & 0.086 & 1.80 & {$[-0.01,0.18]$} & & & & \\
\hline & BMI vs. Gender & 0.052 & 0.62 & {$[-0.12,0.22]$} & & & & \\
\hline
\end{tabular}

Note. $\quad \mathrm{CI}=$ confidence interval; ScreenT $=$ screen time $(\mathrm{TV} /$ Video games $) ; \mathrm{PA}=$ out-of-school physical activity; KIDMED = Mediterranean diet; $\mathrm{BMI}=$ body mass index $(z$-score $)$. Independent variables were mean centered. $\quad * p<.05, * * * p<.001$. 


\section{Discussion}

The purpose of this study was to explore the relationship between screen time behaviour, physical activity, adherence to the Mediterranean diet and BMI with body image dissatisfaction in a sample of primary school children. We also aimed to explore how gender moderates these relationships.

Compared to girls, boys were more active out-ofschool, but adhered less to the Mediterranean diet. Differences in screen time were inexistent. The results concerning gender differences in physical activity are consistent with the literature (e.g., Iannotti et al., 2009). Nevertheless, the effect size was small which may suggest limited practical implications of these differences at these young ages. Indeed, research has shown that physical activity tends to decrease more sharply, particularly among girls, at the onset of adolescence (Marques \& Matos, 2014). Yet, bearing in mind that habits towards active lifestyles develop at an early age and may track into adulthood (Santos, Oliveira, Ribeiro, \& Mota, 2009), practitioners should consider these gender differences when designing interventions.

In the present study, girls scored significantly higher in the KIDMED index than boys, although the effect size was small. For both genders, these scores represent low adherence to the Mediterranean diet, which is in line with studies conducted in Mediterranean countries such as Turkey (Cömert et al., 2015) and Spain (Mariscal-Arcas et al., 2009). Considering that this type of diet protects against a number of health conditions (e.g., obesity, cardiovascular diseases), these results reinforce the need for educational interventions about the benefits of the Mediterranean diet targeting parents or legal tutors and children. Such interventions might be particularly impactful as children become more independent to make their own nutritional choices.

The nonsignificant differences in BMI between boys and girls are contrary to Coelho et al.'s (2013) who identified greater BMI in girls using a large sample of Portuguese schoolchildren. In the present paper, participants were recruited from a small municipality of the southeast region of the country, which may have unique social-economic characteristics that justify the lack of significant differences. Moreover, Coelho et al. seem to use raw BMI, while in the present study we use the World Health Organization $z$-scores, which consider that children's BMI changes during their developmental years and as a function of gender.

Mean values of BMI ( $z$-scores) increased throughout the continuum of the Figure rating scale silhouettes. However, considering the pattern of statistical significance of these differences, the present results support Coelho et al.'s (2013) suggestion of silhouette
5 as a cut-off point to define overweight. Specifically, significant differences in BMI only began to be observed between silhouettes 4 and 5 ; in addition, the majority of the participants who selected silhouette 5 were overweight or obese. Also, it appears that for the current sample silhouettes 1 through 4 did not have discriminative power. The sample sizes for some of these categories may be a limiting factor.

In this study, more than one-third of the children were overweight or obese $(38.1 \%)$ and almost half considered themselves heavier than they really were (45.1\%). In addition, the correlation between BMI and current body image was moderate $(r=.49, p<.001)$. Taken together, these results support the idea that children have imprecise perceptions of their own weight and body (Coelho et al., 2013; Spiel, Paxton, \& Yager, 2012). Such imprecision of self-perceptions may lead to inappropriate weight management strategies. Hence, addressing children's perceptions of their body may be more important for interventions than focussing solely on their actual body size (Assaad et al., 2018).

Although there were no significant differences between genders in relation to BMI and current body image, girls showed significantly higher body image dissatisfaction than boys. Nevertheless, in our study, we observed a significant difference in body image dissatisfaction, which suggests that such internalisation is already taking place. This interpretation is consistent with Ricciardelli and McCabe (2001) discussion that gender differences in body satisfaction are not always found in 6-7-year-olds, but may develop between 8-10 years of age perhaps due to the social-cultural ideals of body size not being internalised before then. In addition, such internalisation is stronger in girls leading to a more negative perception of social cultural pressures compared to boys (Tatangelo \& Ricciardelli, 2015). In fact, girls as young as five years old have been shown to be susceptible to the pressures of peers and social media to achieve a thin body (Damiano, Paxton, Wertheim, McLean, \& Gregg, 2015). Interventions could support girls in the process of reframing and interpreting current social messages related to sociallyprescribed ideal bodies.

Gender and BMI were the only significant predictors of body image dissatisfaction, explaining $0.8 \%$ and $15.5 \%$ of the variance of the predicted variable. Although the percentage of the variance accounted for by gender is trivial, these results suggest that children as young as six to nine years old with higher BMI may be at higher risk of being dissatisfied with their bodies (Coelho et al., 2013; Duchin et al., 2014).

Contrary to expectations, none of the health behaviours were significantly associated with body image dissatisfaction. Nevertheless, similar results 
have been found in the literature. For example, Duncan, Al-Nakeeb, Nevill, and Jones (2004) did not find a relationship between physical activity and body image in pre-adolescent children. However, Katzmarzyk et al. (2015) reported a relationship between moderate-to-vigorous physical activity and screen-viewing time with obesity in 9-11-year-olds. Future research should explore the extent to which BMI mediates the relationship between health behaviours and body dissatisfaction.

Also contrary to expectations, none of the variables, including BMI, interacted with gender to predict body image dissatisfaction, which fails to confirm previous results that overweight girls were more prone to body dissatisfaction than normal-weight girls or boys (Shriver et al., 2013).

This study has a number of limitations. First, it is cross-sectional in nature, which precludes the interpretation of cause-effect between the variables. Second, the measures concerning physical activity and screen time are limited in scope, failing to consider their multidimensional nature. The measure of physical activity did not consider intensity and frequency of the behaviour; the measure of screen time was limited to watching TV and playing videogames and did not consider other forms of screen time (e.g., computer use, mobile phone use) or the time spent in these activities during the weekend, when sedentary pursuits tend to increase the most (Sigmund et al., 2015). However, other researchers (e.g., Largues et al., 2011; Serra-Majem, Bartrina, Pérez-Rodrigo, Ribas-Barba, \& Delgado-Rubio, 2006) have used these simplified measures in consideration to the characteristics of the age group, the large sample size and their time effectiveness. Third, parents completed reports of physical activity and screen time. Although the rationale for using this strategy lies on the limitations of young children to provide accurate estimates of these behaviours, this strategy is less reliable than methods that involve observation or technology (Biddle, Sallis, \& Cavill, 1998).

This study also has a number of strengths. Notably, the sample is composed of a high percentage of all the primary schoolchildren in the southeast region of the country. Also, BMI was calculated with objectively measured weight and height rather than by self-report, which is uncommon in large studies. Therefore, results are likely to be generalizable to the population of primary school students in this municipality.

\section{Conclusions}

Physical activity, screen time, and adherence to the Mediterranean diet were not associated with body image dissatisfaction; however, BMI was positively associated with body dissatisfaction in a sample of primary school children.

\section{Conflict of interest}

There were no conflicts of interest.

\section{References}

Adami, F., Frainer, D. E. S., de Souza Almeida, F., de Abreu, L. C., Valenti, V. E., Demarzo, M. M. P., ... de Oliveira, F. R. (2012). Construct validity of a figure rating scale for Brazilian adolescents. Nutrition Journal, 11, 24.

Ali, M. M., Fang, H., \& Rizzo, J. A. (2010). Body weight, self-perception and mental health outcomes among adolescents. Journal of Mental Health Policy and Economics, 13, 53-63.

Andersen, R. E., Crespo, C. J., Bartlett, S. J., Cheskin, L. J., \& Pratt, M. (1998). Relationship of physical activity and television watching with body weight and level of fatness among children: Results from the Third National Health and Nutrition Examination Survey. JAMA, 279, 938-942.

Assaad, S., Anouti, S., Naja, F., Nasreddine, L., Hwalla, N., \& Sibai, A. M. (2018). Adolescents' self-perceived and actual weight: Which plays a dominant role in weight loss behaviour in Lebanon? Child: Care Health and Development, 44, 124-130.

Biddle, S. J. H., Sallis, J. F., \& Cavill, N. (1998). Young and active: Physical activity guidelines for young people in the UK. London, United Kingdom: Health Education Authority.

Brill, J. B. (2009). The Mediterranean diet and your health. American Journal of Lifestyle Medicine, 3, 44-56.

Calmeiro, L., \& Matos, M. (2016). Health assets and active lifestyles during pre-adolescence and adolescence: Highlights from the $\mathrm{HBSC} / \mathrm{WHO}$ health survey and implications to health promotion. In M. Raab, P. Wylleman, R. Seiler, A.-M. Elbe, \& A. Hatzigeorgiadis (Eds.), Sport and exercise psychology research: From theory to practice (pp. 443-460). Amsterdam, Netherlands: Elsevier.

Coelho, E. M., Padez, C., Moreira, P., Rosado, V., \& MouraoCarvalhal, I. (2013). IMC y percepción de la forma del cuerpo en niños portugueses [BMI and self-perceived body shape in Portuguese children]. Revista de Psicologia del Deporte, 22, 371-376.

Cohen, J. (1988). Statistical power analysis for the behavioral sciences (2nd ed.). Hillsdale, NJ: Erlbaum.

Cole, T. J., Bellizzi, M. C., Flegal, K. M., \& Dietz, W. H. (2000). Establishing a standard definition for child overweight and obesity worlwide: International survey. British Medical Journal, 320, 1240.

Cömert, T. K., Çerkez, M., Tekin, A. G., Aydoğan, N., \& Esşiz, Ö. (2015). Compliance with Mediterranean Diet Quality Index (Kidmed) and eating patterns in school-age children with Gaziantep, Turkey. American Journal of Food and Nutrition, 3, 28-33.

Damiano, S. R., Paxton, S. J., Wertheim, E. H., McLean, S. A., \& Gregg, K. J. (2015). Dietary restraint of 5-year-old 
girls: Associations with internalization of the thin ideal and maternal, media, and peer influences. International Journal of Eating Disorders, 48, 1166-1169.

Davis, C. (1997). Body image, exercise, and eating behaviors. In K. R. Fox (Ed.), The physical self: From motivation to well-being (pp. 143-174). Champaign, IL: Human Kinetics.

Dion, J., Hains, J., Vachon, P., Plouffe, J., Laberge, L., Perron, M., ... Leone, M. (2016). Correlates of body dissatisfaction in children. Journal of Pediatrics, 171, 202-207.

Dohnt, H. K., \& Tiggemann, M. (2006). Body image concerns in young girls: The role of peers and media prior to adolescence. Journal of Youth and Adolescence, 35, 135.

Duchin, O., Marin, C., Mora-Plazas, M., de Leon, C. M., Lee, J. M., Baylin, A., \& Villamor, E. (2015). A prospective study of body image dissatisfaction and BMI change in school-age children. Public Health Nutrition, 18, 322-328.

Duchin, O., Mora-Plazas, M., Marin, C., de Leon, C. M., Lee, J. M., Baylin, A., \& Villamor, E. (2014). BMI and sociodemographic correlates of body image perception and attitudes in school-aged children. Public Health Nutrition, 17, 2216-2225.

Duncan, M. J., Al-Nakeeb, Y., Nevill, A., \& Jones, M. V. (2004). Body image and physical activity in British secondary school children. European Physical Education Review, 10, 243-260.

Iannotti, R. J., Janssen, I., Haug, E., Kololo, H., Annaheim, B., Borraccino, A., \& HBSC Physical Activity Focus Group (2009). Interrelationships of adolescent physical activity, screen-based sedentary behaviour, and social and psychological health. International Journal of Public Health, 54, 191-198.

Katzmarzyk, P. T., Barreira, T. V., Broyles, S. T., Champagne, C. M., Chaput, J. P., Fogelholm, M., ... Lambert, E. V. (2015). Relationship between lifestyle behaviors and obesity in children ages 9-11: Results from a 12-country study. Obesity, 23, 1696-1702.

Leal, F. M. R., Oliveira, B. M. P. M., \& Pereira, S. S. R. (2011). Relationship between cooking habits and skills and Mediterranean diet in a sample of Portuguese adolescents. Perspectives in Public Health, 131, 283-287.

Llargues, E., Franco, R., Recasens, A., Nadal, A., Vila, M., Pérez, M. J., ... Roure, E. (2011). Assessment of a schoolbased intervention in eating habits and physical activity in school children: The AVall study. Journal of Epidemiology \& Community Health, 65, 896-901.

Mariscal-Arcas, M., Rivas, A., Velasco, J., Ortega, M., Caballero, A. M., \& Olea-Serrano, F. (2009). Evaluation of the Mediterranean Diet Quality Index (KIDMED) in children and adolescents in Southern Spain. Public Health Nutrition, 12, 1408-1412.

Marques, A., \& Matos, M. G. (2014). Adolescents' physical activity trends over the years: A three-cohort study based on the Health Behaviour in School-aged Children (HBSC) Portuguese survey. BMJ Open, 4, e006012.

Padez, C., Fernandes, T., Mourão, I., Moreira, P., \& Rosado, V. (2004). Prevalence of overweight and obesity in 7-9-year-old Portuguese children: Trends in body mass index from 1970-2002. American Journal of Human Biology, 16, 670-678.

Petracci, E., \& Cavrini, G. (2013). The effect of weight status, lifestyle, and body image perception on health-related quality of life in children: A quantile approach. Quality of Life Research, 22, 2607-2615.

Ricciardelli, L. A., \& McCabe, M. P. (2001). Children's body image concerns and eating disturbance: A review of the literature. Clinical Psychology Review, 21, 325-344.

Sands, R., Tricker, J., Sherman, C., Armatas, C., \& Maschette, W. (1997). Disordered eating patterns, body image, selfesteem, and physical activity in preadolescent school children. International Journal of Eating Disorders, 21, 159-166.

Santos, M. P., Oliveira, J., Ribeiro, J. C., \& Mota, J. (2009). Active travel to school, BMI and participation in organised and non-organised physical activity among Portuguese adolescents. Preventive Medicine, 49, 497-499.

Scagliusi, F. B., Alvarenga, M., Polacow, V. O., Cordás, T. A., de Oliveira Queiroz, G. K., Coelho, D., ... Lancha, A. H., Jr. (2006). Concurrent and discriminant validity of the Stunkard's figure rating scale adapted into Portuguese. Appetite, 47, 77-82.

Serra-Majem, L., Bartrina, J. A., Pérez-Rodrigo, C., RibasBarba, L., \& Delgado-Rubio, A. (2006). Prevalence and determinants of obesity in Spanish children and young people. British Journal of Nutrition, 96(S1), S67-S72.

Serra-Majem, L., Ribas, L., Ngo, J., Ortega, R. M., García, A., Pérez-Rodrigo, C., \& Aranceta, J. (2004). Food, youth and the Mediterranean diet in Spain. Development of KIDMED, Mediterranean Diet Quality Index in children and adolescents. Public Health Nutrition, 7, 931-935.

Shriver, L. H., Harrist, A. W., Page, M., Hubbs-Tait, L., Moulton, M., \& Topham, G. (2013). Differences in body esteem by weight status, gender, and physical activity among young elementary school-aged children. Body Image, 10, 78-84.

Sigmund, E., Sigmundová, D., Badura, P., Kalman, M., Hamrik, Z., \& Pavelka, J. (2015). Temporal trends in overweight and obesity, physical activity and screen time among Czech adolescents from 2002 to 2014: A national health behaviour in school-aged children study. International Journal of Environmental Research and Public Health, 12, 11848-11868.

Spiel, E. C., Paxton, S. J., \& Yager, Z. (2012). Weight attitudes in 3- to 5-year-old children: Age differences and crosssectional predictors. Body Image, 9, 524-527.

Smolak, L. (2011). Body image development in childhood. In T. Cash \& L. Smolak (Eds.), Body image: A handbook of science, practice and prevention (pp. 67-75). New York, NY: Guildford Press.

Stunkard, A. J., Sorenson, T., \& Schulsinger, F. (1983). Use of the Danish adoption register for the study of obesity and thinness. In S. Kety (Ed.), The genetics of neurological and psychiatric disorders (pp. 115-129). New York, NY: Raven Press.

Tatangelo, G. L., \& Ricciardelli, L. A. (2015). Children's body image and social comparisons with peers and the media. Journal of Health Psychology, 22, 776-787.

Trost, S. G., Kerr, L. M., Ward, D. S., \& Pate, R. R. (2001). Physical activity and determinants of physical activity in obese and non-obese children. International Journal of Obesity, 25, 822-829.

Wijnhoven, T. M. A., Van Raaij, J. M. A., Spinelli, A., Rito, A. I., Hovengen, R., Kunesova, M., ... O'Dwyer, U. (2013). WHO European Childhood Obesity Surveillance Initiative 2008: Weight, height and body mass index in 6-9-year-old children. Pediatric Obesity, 8, 79-97. 